\section{Visión Electrónica Más que un estado sólido \\ https://doi.org/10.14483/issn.2248-4728}

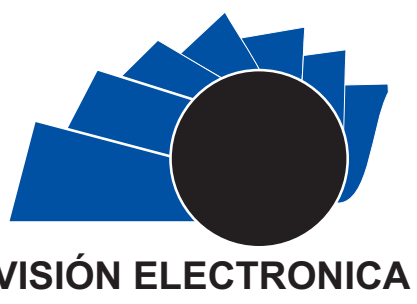

A Research Vision

\title{
Evolution of ambulatory measurement for the detection of heart diseases
}

\author{
Evolución de la medición ambulatoria para la detección de enfermedades cardiacas
}

\author{
Lilia Edith Aparicio-Pico ${ }^{1}$, Astrid Ramirez-Valencia ${ }^{2}$, \\ Juan Carlos Mateus-Silva ${ }^{3}$
}

\section{INFORMACIÓN DEL ARTICULO}

Historia del articulo

Enviado: 23/10/2018

Recibido: 05/11/2018

Aceptado: 25/11/2018

\section{Keywords:}

Ambulatory measurement

device,

Cardiac diseases,

Holter monitor.

\section{Palabras clave:}

Dispositivos de medición ambulatoria,

Enfermedades cardiacas, Monitor Holter.

\section{ABSTRACT}

Since the appearance of the Holter monitor, it was conceived as a continuation of the electrocardiogram which serves to detect cardiac diseases, many signs of progress have been made of these devices, which go hand in hand with technology, mainly in elements microcontrollers and micro sensors, such as the transmission of data in real time. With this has been minimized the shortcomings to provide greater comfort and better results of the analysis.

This article contains an analysis of these ambulatory measuring devices from the beginning to the current research, analyzing the use of this element for the detection of cardiac diseases, pros and cons of this kind of devices by emphasizing great change that has been generated in recent years with the technological progress.

\section{RESUMEN:}

Desde la aparición del monitor Holter concebido como una continuación del electrocardiograma que sirve para detectar enfermedades cardiacas, se han presentado avances de estos dispositivos los cuales van de la mano con la tecnología, principalmente en elementos microcontroladores y microsensores, como la transmisión de datos en tiempo real, con esto han sido minimizadas las falencias para brindar mayor comodidad y mejores resultados de análisis. El presente artículo contiene un análisis de estos dispositivos de medición ambulatoria desde sus inicios hasta las investigaciones actuales, analizando el uso de este elemento para la detección de enfermedades cardiacas, pros y contra de esta clase de dispositivos y del gran cambio que se ha generado en los últimos años con el progreso tecnológico

\footnotetext{
${ }^{1}$ BSc. In Physics, Universidad Distrital Francisco José de Caldas, Colombia. Specialist in Project managing, MSc. In Teleinformatics, Universidad Distrital Francisco José de Caldas, Colombia, Ph.D. In Technical Sciences, Universidad Marta Abreu Las Villas, Cuba. Current position: Professor at Universidad Distrital Francisco José de Caldas, Colombia, Director group GITEM++, Colombia: e-mail: leap0763@gmail.com. medicina@udistrital.edu.co. ORCID: https://orcid.org/0000-0003-1841-4423.

${ }^{2}$ BSc. In Spanish-English, Universidad Distrital Francisco José de Caldas, Colombia. MSc. In Linguistics Applied to the Teaching of English, Universidad Distrital Francisco José de Caldas, Colombia. Ph.D. (c) In Language and Culture, Universidad Pedagógica y Tecnológica de Colombia, Tunja, Colombia. Current position: Member of the group GITEM++, Universidad Distrital Francisco José de Caldas, Colombia. E-mail: astramirez@gmail.com. aramirezv@udistrital.edu.co. ORCID: https://orcid.org/o000-00023025-5982.

${ }^{3}$ BSc. In Electronic Enginnering, Universidad Distrital Francisco José de Caldas, Colombia. Current position: Member of the group GlTEM++, Universidad Distrital Francisco José de Caldas, Colombia. E-mail: jcmateuss@udistrital.edu.co, juancarlos.m.s@hotmail.com, jcmateuss@.correo.udistrital.edu.co. ORCID: https://orcid.org/0000-0003-4363$\underline{3791 .}$

Cite this article as: L. E. Aparicio-Pico, A. Ramírez-Valencia and J. C. Mateus-Silva, "Evolution of ambulatory measurement for the detection of heart diseases", Visión electrónica, algo más que un estado sólido, vol. 1, no. 2, Special edition, july-december 2018. DOI revista: $\underline{\text { https://doi.org/10.14483/issn.2248-4728 }}$
} 


\section{Introduction}

Decades have happened since the Holter Monitor made its appearance in the medicine field, being recognized as the ambulatory electrocardiograph for excellence, since its functioning for the cardiac illnesses' detection for its long sample period has facilitated the detection of diverse types of atypical activities in the behavior of the heart, especially when daily activities are practiced like going down for stairs or sleeping, which cannot be easily detected by an electrocardiogram which does not take any more time of 2 minutes in its measurement time, but, why has this monitor dropped to comparison of the electrocardiogram? Many people affirm that the loyalty of the result changes in the course of time, also the movement of the sensors generates distortions as the electrocardiographs take more reference points which give more safety in the diagnosis and recognizes numerous heart disease, people avoid their use because of the discomfort of electrodes and cables about noninvasive devices, in addition to waiting a long time for a specialist to review the sample and generate a diagnosis, this kind things create discomfort when using a monitor; For these reasons, it was necessary for the technology to generate a contribution in this device and in the electrocardiography itself, this was why bioengineering has allowed new elements to evolve in this kind analysis, which seeks to fulfill its special function and deliver more than its predecessors, substantially improving its functioning for improving the diagnosis, the prevention, and the reaction to heart disease.

\section{Evolution of the devices}

To observe the advances that have been generated in the last decades, it is necessary to evaluate the information of the devices that has progressed over time, the most significant changes make possible to differentiate two great generations, which are described below.

\subsection{First generation devices}

The Holter Monitor (which was the first one to make its appearance), captures the ECG signals by electrodes located at specific points to measure the heart rate, it usually can be 2 to 7 shunts and 3 to 12 channels [1], this device has an approximate dimension of $70 \times 95 \times 20$ $\mathrm{mm}$; Weight, $\approx 190$ grams [2] the signal takes a pass through filters system type that rejects band and passes other ones to separate the important information from the noise, It is accompanied by an amplification stage so that the information obtained can be observed, since these signals are in millivolts, at the end of this stage there is an analog-digital converter which is in charge of the discretized signal Which is stored in a memory, usually flash-type or SD, which has a specific format in some cases.

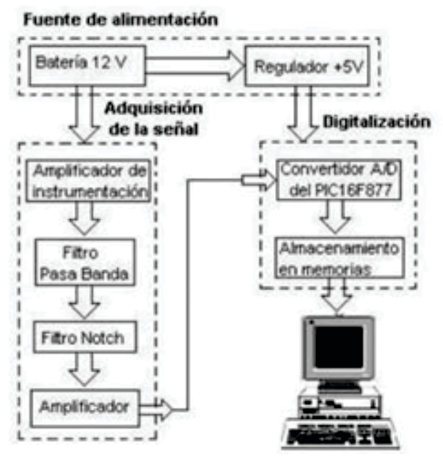

Figure 1. Diagram of blocks of a Holter monitor, [3].

In Figure 1, it can be observed that for the detection of the diseases that can be found in a monitor of this type, it is necessary that this information must be reviewed by a computer that has the software allowed by the company manufacturer of the device, normally, this study can take some days to determine a diagnosis, this situation makes it tedious and impractical. There is a device similar to the Holter Monitor, with the same function and purpose, the difference with the Holter monitor is that it does not take samples at all the time of use, this stores the information when the patient activates a button at the time when he or she feels a symptom of a possible disease [4].

With the emergence of telemedicine, the transmission of information of these elements in real time is made possible, at the beginning, Willem Einthoven, Nobel Prize of Medicine by the invention of the electrocardiograph, sent the information of its study on Electrocardiography by means of a telephone cable to 1.5 kilometers of distance [5], with the appearance of the mobile telephony, it was sought a use for them apart from the communication voice to voice, using this type of investigation

It was possible to transmit data of any kind, even those generated by biomedical devices, with this appeared devices capable of transmitting signals "in real time" using telephony networks $2 \mathrm{~g}$ and $3 \mathrm{~g}[6,8]$, in addition to $\mathrm{Wi}-\mathrm{Fi}$ and Interconnecting with receiver modules and transmitters via Bluetooth, some of these devices are commercial and are mentioned in some compilations made by large entities in the cardiology area [7].

This type of solution minimized some of the negative aspects of electrocardiographs, including outpatient 
(the time of waiting for a diagnosis), which created the monitoring feedback, that is a device that works just like the Holter monitor, its difference is that the information supplied by the device is delivered to a remote port in which it is stored and distributed to the people who want the information, For example, the Doctor who has applied for the test, with this, if there is a trauma or anomaly in the sample period, can take the necessary actions to prevent illnesses or possible conditions that may cost life. This is the slogan of some system creators like Cardio Smart [6], the wireless telemonitoring system of cardiac events Wham [9] that, using $2 \mathrm{~g}$ telephony and Wi-Fi or Bluetooth networks, carry out a transmission of data collected by various sensors at different points of the body to be collected and studied in real time, normally used with high performance athletes for the study and the improvement of their activities that yield a physical effort.

Evolutions like these that have appeared since the year 2005, have created advances to minimize one of the main flaws of the monitor, but there was still the disadvantage on its comfort.

\subsection{Devices of second generation}

The great virtue of the current engineering is the minimization of the electronic components from the transistors to the logical units that have changed the sizes of the elements and considerably improved their operation, this has been used for that Biomedical elements that can also generate their progress and change in favor of their science, in this case, research has been conducted ranging from sensors that do not need to be directly connected to the patient (vests or flannels with sensors and micro cables that can take samples with great fidelity $[8,10]$ or use of Bluetooth for communication between devices like Telesmart of the company Medset [11]) until the creation of waterresistant sensors united to a Device that covers a small space but that can become more efficient than the conventional monitor.

With these advancement emergences appear the ECG patches that are devices of a small size less than the conventional, which it is only necessary to be placed in the chest on the correct site for being responsible for taking the same signals with more efficiency and comfort, its sampling time can reach up two weeks later, having two or three electrodes to take measurements in the intercostals points, and the anatomical shape that they have by allowing a major maneuverability and comfort at the moment to use it, besides; the fact that the results offered show superiority to the Holter Monitor classic. [12]

Among the devices that have obtained a greater recognition, it is counted with ZIO, of the IRhythm [13] company, which is non-invasive, with less size than 10 centimeters and with a 92 possibility of detection of different types of illnesses that compared with the Holter Monitor that can only detect 61.In addition, people who have made the test confirm that they find the patch more comfortable in a $93.7 \%$ and Superior in an $81 \%$ in comparison with the Holter Monitor [10], one of the main advantages of this device, is that it is unnecessary to keep a diary, it combines the detection of a Holter device with a detector of an event, since the patient can press a button when he/she feels any inconvenience and the system will mark that time to be studied later, the common point that they have is that their diagnosis is delivered after being returned the device to the manufacturer which is responsible for conducting the analysis, But the device manufacturer delivers the diagnosis within one or two days through a Web page. Figure 2, shows the ZIO device and its result sheet sent by the web to patient. over a patient's internet.

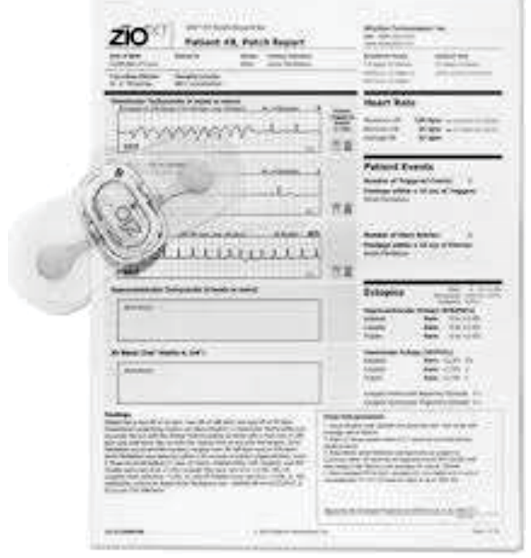

Figure 2. Patch Holter $\mathrm{ZIO}$ of the IRhithm and its diagnosis sheet, [14].

The current situation has not stopped with ZIO and its revolutionary structure, new devices appear that have special adaptations, these patches combine the use of the data transmission in real time with the comfort that can generate this kind of elements, as a comparison of the iRhythm device, these elements transmit and are evaluated by a team of specialists which can inform the doctor responsible for the process and the kind of anomalies that have been presented and their reaction for the prevention and rapid response in case of any trauma, these are known as Mobile cardiac telemetry Systems or MCT (Mobile Cardiac Telemetry), examples of this kind of devices are V-Patch of the Chennai Indian company [15] and SEEQ MCT the Medtronic American company. [16] 


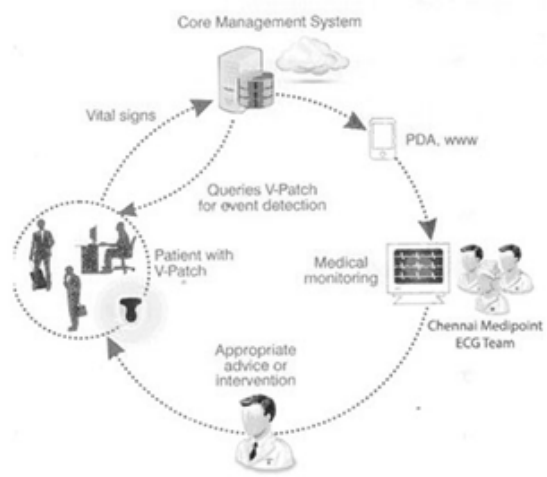

Figure 3. Real-time mobile telemetry system operation, [15].

In Figure 3, it is shown how the device expresses the vital signs to a normally recipient by Bluetooth, the information is sent to a storage system by GPRS $(2 \mathrm{G})$ in case of V-Patch, to be checked by a medical body, delivering the information gathered by a virtual assistant, mobile phone or for a page coded in the web, if some anomaly is detected in the time of sampling, the personnel in charge of the monitoring will inform the doctor that has requested the review, this information will be requested to the family members or people who can be intervened in case of risk to life. Today, the Chinese and American industry continues to evolve, to the point of creating much smaller and more comfortable devices, capable of recognizing ECG signals, temperature, activities like walking and detecting falls, with applications for cell phone in which can be monitored the health person status using the patch, they are devices like Heart Book MCT [16] and Health Patch MD of Vital Connect Company [17] which can have a cost between 90 and 200 dollars and have a great resemblance to devices used by high performance athletes like soccer players and cyclists, but this is not only used for this kind of activities, Health patch MD has been used for the monitoring people who suffer sleep apnea syndrome by generating great results in comfort and event detection. [18].

The technology continues with a strong evolution, the monitors are becoming smaller and with greater functionality, this kind of non-invasive monitors have revolutionized the way to perform a monitoring for the detection of heart disease and have joined other sensors to create devices that can take multiple vital signs by making easier and more comfortable the patients 'life, devices like VitalPatch [19] is created by the Vital Connect company, which has multiple qualities (heart rate, HVR, respiratory rate, skin temperature, body posture, fall a detector and activity) in a device not higher than 8 centimeters thick, 11 grams' weight and a less than 100 dollars' value, this patch offers to the Hospitals the service of patients monitoring, the results thrown their research groups have shown that this kind of devices can be useful in any field and it can be used by any person, too.

Furthermore, this device is joined by several manufacturers, who continue to innovate in its structural form and in the internal elements to generate greater comfort and benefits, among them we can find devices like the biosensor placed by the company Phillips [20] or Life-watch of the company Biotelemetry Inc. [21].

\subsection{Operation of a second-generation device}

To understand how this kind of devices works, mainly those with the most functions included, an MCT device is taken into account [22], consists of a disposable adhesive patch sensor that incorporates two or three electrodes (about patches ECG) surface with a hydrogel, these electrodes are composed of silver chloride $(\mathrm{AgCl})$, which to be connected to the patient has to meet certain conditions such as: the patient's Chest. It must be shaved and free of dead cell and speed, in addition to keeping in mind the correct use of the electrodes, and their expiration time. Most ECG patch monitors, event recorders, and MCT monitors available today have a single derivative of two embedded electrodes or tightly spaced cabling. A variety of single-wire configurations is only possible on cable electrode systems, the most common being a modified V5 with the chest (CM5), a modified V3 with the chest (CM3) and a modified bottom cable. The configurations that could be implemented can be chosen in specific situations for example, about a patient subjected to ambulatory ECG monitoring for an ischemia, the configuration of the ambulatory electrocardiogram should be chosen for Mimic the derivations with the greatest change in the ST segment during exercise. The ambulatory ECG cannot be considered equivalent to standard ECG for all purposes and should not be used interchangeably with the standard ECG for serial comparison. For example, a 12-lead ECG is the diagnostic test of choice for long QT syndrome (LQTS), rather than an ambulatory ECG. Other elements that have some devices, like the SEEQ which not only have Holter detection, is a thermistor at the bottom of the patch, a battery and an electronic module with a built-in processor, Microelectromechanic accelerometer of triaxial system and a Bluetooth module with low power consumption (BLE) [21]. The patch sensor facilitates continuous monitoring of a 
single-wire bipolar ECG and human body acceleration signals. (with a $4 \mathrm{~g}$ range where $\mathrm{G}=9.81 \mathrm{~m} / \mathrm{s} 2$ and a $0.0078 \mathrm{~g}$ resolution) at a sampling rate of 125 and 62.5 $\mathrm{Hz}$, respectively. The device automatically performs the accelerometer calibration to obtain vertical images, anteroposterior and left-right side directions for an initial standing or walking period.In the same way, to understand the device's software, it is necessary to analyze that the firmware algorithm in the electronic module processes the initial signals and transmits a current of physiological data, measures as encrypted data that include heart rate, Heart rate variability, respiration rate, skin temperature, posture, step, and fall detection through a wireless BLE protocol [22] encrypted for a relay as a smartphone, where direct and real streaming data can be viewed and saved. The Relay Software library manages bidirectional communication between the patch sensor and the server's software library and is installed on a relay device.

The server's software library is installed on a central server, manages the load, processing, and storage of sensor data, as well as real-time configuration and platform notifications. [23]

On the top of that, the use of Holter patches have delivered positive results, for example, the device SEEQ
MCT reports that the device conformity is $90 \%$ compared to the conventional monitor, because this restricts daily events such as showering and is uncomfortable for being used at the time to go sleeping, in addition its performance in the diagnosis is greater, according with the patients who used the patch that found a $63 \%$ detection of anomalies in comparison with the $13 \%$ offered by a conventional monitor. Finally, contemplating its benefits, the study time is much lower than its predecessor, as it can be seen a sample of 5.8 days compared to the months that can accrue an analysis with a traditional Holter. [23]

\subsection{Advantages and disadvantages of first and second generation devices}

The advantages of second-generation devices highlight the shortcomings of their predecessors, but it is necessary to understand that technology has a training process and there are still no "perfect machines", in this case, second-generation devices have deficiencies, but they are minuscule in comparison with the first generation monitors. Table 1, shows some of the advantages and disadvantages of the different first-and second-generation devices. [24]

\begin{tabular}{|c|c|c|}
\hline $\begin{array}{c}\text { ECG Monitoring } \\
\text { Technique }\end{array}$ & Advantages & Disadvantages \\
\hline $\begin{array}{l}\text { Holter } \\
\text { Monitor }\end{array}$ & $\begin{array}{l}\text { Ability to continuously store and document 3-to } \\
\text { 12-way ECG signals simultaneously with a } \\
\text { variety of other biological cues during daily life } \\
\text { activities. } \\
\text { Friendly with specialists for their analysis } \\
\text { program and a wide availability of scanning } \\
\text { services that can be generated outside the } \\
\text { equipment for diagnostic reports. }\end{array}$ & $\begin{array}{l}\text {-Frequent discord with event logs and events markers. } \\
\text {-Frequent disconnection of electrodes. } \\
\text {-The quality of the signal depends on the adhesion of the } \\
\text { electrode to the skin, the tangle of cables and the } \\
\text { occasional generation of dermatitis by the gel of the } \\
\text { electrodes. } \\
\text {-No real-time data analysis. } \\
\text {-Little acceptance of electrode systems by patients. }\end{array}$ \\
\hline $\begin{array}{c}\text { ECG } \\
\text { Patches }\end{array}$ & $\begin{array}{l}\text {-Long-time storage (14 days or more). } \\
\text {-Excellent acceptance on the part of patients. }\end{array}$ & $\begin{array}{l}\text {-It stores an ECG signal limited by the short space of its } \\
\text { sensors, compressing the sequence of waves } \mathrm{P}, \mathrm{Q}, \mathrm{R}, \mathrm{S} \text { and } \\
\mathrm{T} \text { with a low amplitude of voltage, therefore, it lacks the } \\
\text { capacity of location of arrhythmias. } \\
\text {-ECG signals inconsistent with the difference in body } \\
\text { types }\end{array}$ \\
\hline $\begin{array}{c}\text { External } \\
\text { loops } \\
\text { recorders }\end{array}$ & $\begin{array}{l}\text {-Stores only the ECG segments selected from a } \\
\text { fixed duration after an event detected by the } \\
\text { patient. } \\
\text {-Generating an immediate alarm on the detection } \\
\text { of the event. } \\
\text {-Well tolerated by the patient. }\end{array}$ & $\begin{array}{l}\text {-Single-way devices do not indicate the origin of many } \\
\text { arrhythmias. } \\
\text {-Does not have the ability to continually store heart rate. } \\
\text {-Diagnostic performance highly depends on the patient's } \\
\text { knowledge of the symptoms. }\end{array}$ \\
\hline
\end{tabular}




\begin{tabular}{|c|c|c|}
\hline $\begin{array}{c}\text { ECG Monitoring } \\
\text { Technique }\end{array}$ & Advantages & Disadvantages \\
\hline $\begin{array}{c}\text { Event } \\
\text { recorders }\end{array}$ & $\begin{array}{l}\text {-Stores only at selected ECG moments of fixed } \\
\text { duration marked as an event either automatically } \\
\text { or manually by the patient. } \\
\text {-Generation of an immediate alarm on the } \\
\text { detection of the event. }\end{array}$ & $\begin{array}{l}\text {-It stores an ECG signal limited by the short space of its } \\
\text { sensors, compressing the sequence of waves } \mathrm{P}, \mathrm{Q}, \mathrm{R}, \mathrm{S} \text { and } \\
\mathrm{T} \text { with a low amplitude of voltage, therefore, it lacks the } \\
\text { capacity of location of arrhythmias. } \\
\text {-Does not have the ability to continually store heart rate } \\
\text {-Requires patients to use and change electrodes frequently } \\
\text { during study time. }\end{array}$ \\
\hline $\begin{array}{c}\text { Telemetry } \\
\text { cardiac } \\
\text { mobile } \\
\text { (TCM) }\end{array}$ & $\begin{array}{l}\text {-Multi-way MCT can store a pseudo-standard 3- } \\
\text { way electrocardiogram, therefore, have greater } \\
\text { sensitivity and are more specific at the time of } \\
\text { detecting arrhythmias compared to single-way } \\
\text { devices. } \\
\text {-It can generate a continuous transmission of the } \\
\text { data obtained (streaming) to be delivered to } \\
\text { nurses or people who care for the patient, } \\
\text { combines the operation of a traditional Holter. }\end{array}$ & $\begin{array}{l}\text {-Some MTC are wired, they ask for the electrodes to be } \\
\text { changed daily, which can cause discomfort to the patient }\end{array}$ \\
\hline
\end{tabular}

Table 1. Advantages and disadvantages of the devices of first and second generation, [24].

It is observed that, although this kind of secondgeneration devices suppress the vast majority of the drawbacks that their predecessors have, however, they have limitations, which, many of them are in study to provide an integral device, to Still, the current MCT devices have considerably reduced their size, increased their efficiency and integrated multiple sensors, which allow continuous monitoring to be optimal so they become the best. So they become the best option for the detection not only of cardiac diseases also of other types of conditions, creating an integral device for human health.

\subsection{Recommendations}

Most of the MCT devices (which may be considered the most evolved) have reported success stories in clinics that have applied for study [25-27], in which patients have informed greater comfort in the use and equipment Doctors like family members have given their approval to this kind of monitoring elements, but this kind of devices can also be of public use because some of them can be easily acquired in the market, for a correct diagnosis should be followed certain steps, which can be delivered by the same doctor who has knowledge On the device, or some manufacturers teach how to use them and apply them to obtain a good result [28-29], which makes these elements easy to use and fulfill their function fully.

Additionally, depending on the device the information can be delivered to the doctor in real time or it can be stored so that it can be disclosed when you have any questions or concerns. Given the situation of its current costs, the greater the technology has the device (MCT) to the minor (Holter), the difference can be considerable for the amount of benefits that can have this type of service, in addition that in the market is achieved some Shunt devices from 70 dollars, which is an affordable price being aware of the Holter value [30]. We can also observe that, with the minimization of the devices, there have appeared additions to intelligent elements such as intelligent clocks (smartwatch) or magnetic bands, which offer some services, but you cannot compare the quality of the Information obtained by the ECG devices with what they offer these gadgets of some technology manufacturers [31].

It is also emphasizable its capacity of innovation to optimize its devices, one of them is achieved by the American company Apple with its smartwatch Apple Watch, who in its next generation of device wants to include in the belt a metal plate which will serve as a sensor to measure an ECG signal [32]. This strap on your wrist will cost about $\$ 200$ dollars and you'll need an addition of $\$ 99$ dollars for a subscription, which will allow the storage of the information collected. With this Apple seeks to improve its measurements as currently its device measures heart rate with infrared sensors, which, as mentioned above, does not have total reliability compared to a Holter Monitor. 


\subsection{Current researchers}

There are currently great advances in technology, for example, South Korean scientists have achieved the creation of a non-invasive Holter monitor 4 centimeters long and 0.004 millimeters thick [33], which has the same powers as a monitor Conventional, but with the advantage that is located on the wrist and its size is almost imperceptible, It is composed of Microsensors united with a chain of amplifiers to achieve the signals, in addition to securing their storage with a silicone membrane containing Nano gold particles, which favor their stability and memory, will minimize the Technology and these devices will be less perceptible, without leaving aside the obtained scopes and the basic functionality of the ambulatory electrocardiographs.

Not only will the inclusion of nanoparticles be one of the new technologies, as some textile manufacturers have searched for ways to embed small cabling into the fibers of their garments to function as sensors [34], which insert small Interlaced metal conduits in cotton and wool fibers to be used as electrodes, manufacturers of electronic bands for the measurement of ECG signals as the inclusion of electrodes in smartwatch like the Apple watch mentioned above, but we must also include the technological advances that affect secondgeneration devices, one of the main concerns of the revolution that is in training in global communication, the Internet of the Things (IoT) [35] and the Internet of the Whole (IoE) [36], these two concepts will carry hand with the use of the INTERNET IPV6 protocol [37] as replacement of the already nearly exhausted Ipv4 connection to all.

Each of the devices that are in our environment, with strong systems of protection in the cloud or fog depending on the case, which will be part of a large global information network, which works with a new technology in telecommunications Mobile, the new Red5G [38], which has shown in its preliminary tests to have a speed 10 times greater than the Tecnología $4 \mathrm{G}$, this kind of technology will be implemented approximately in the year 2020.

With the technological advances that are expected in the next 15 years (time considering investments, standardization and implementation), we will be able to be connected to a health network at all times, transmitting in real time our vital signs and allowing That prevention and rapid incident action should be effective in minimizing deaths from heart disease.

\section{Conclusions}

- Holter devices provide a greater spectrum of study in the electrocardiography, but have limitations, which have been reduced in recent years thanks to the evolution of bioengineering and electronics.

- As in the first generation, there are a variety of second generation devices that have certain differences between them, some have different elements than the typical ECG signal measuring element which increases the utility and benefits of the devices, but it increases their cost, too.

- Second generation devices have found the main flaws of the first monitors, but they still need to solve some drawbacks to become an integral device.

- Second-generation devices have incorporated new technologies such as IPV6, Internet of Things (IoT) and Bluetooth Low Energy (BLE) in order to improve their performance and use, in comparison to the first-generation elements.

- The future of this kind of technology will create devices that are more reliable, comfortable, manipulatable, and with many functionalities, taking with it not only the purpose of the detection of cardiac diseases, but also, the improvement of the way of life.

\section{References}

[1] Texas Heart Institute, "Estudio Holter", 2018. [O n l ine ]. Ava i l a ble a t: https://www.texasheart.org/hearthealth/heart-informationcenter/topics/estudio-holter/.

[2] P. Zimetbaum and A. Goldman, "Ambulatory Arrhythmia Monitoring Choosing the Right Device", Circulation, vol. 122, no. 16, 2010, pp. $\begin{array}{llllllllll}1 & 6 & 2 & 9 & - & 1 & 6 & 3 & 6\end{array}$. https://doi.org/10.1161/CIRCULATIONA HA.109.925610. .

[3] J. E. Quintero and J. M. Sierra, "Diseño y Construcción de un Prototipo de Electrocardiografía Dinámica "Holter" 
Universal de Tres Canales con Interfaz Electrónica para Cualquier Plataforma de Instrumentación Virtual", Publicaciones $e$ Investigación, vol. 7, 2013, pp. 99, 2013. https://doi.org/10.22490/25394088.1097.

[4] Krames, "Holter ambulatorio y monitor de eventos", 2018. [Online]. Available at:

http://www.veteranshealthlibrary.org/Spani sh/Flipbooks/Cardiology/2291933es VA.p $\underline{\mathrm{df}}$.

[5] Centro médico Escuela, "Historia del desarrollo del Electrocardiógrafo", 2018. [Online]. Available at:

http://www.electrocardiograma.org/historiadel-electrocardiografo.html.

[6] J. Quero, M. Elena, J. Segovia, C. Tarrida, J. Santana and C. Santana, "CardioSmart: Cardiological Monitoring Intelligent system using GPRS", IEEE Latin America Transactions, vol. 3, no. 2, 2005, p p . $152-158$.

https://doi.org/10.1109/TLA.2005.1642403.

[7] M. Brignole, et al., "Indications for the use of diagnostic implantable and external ECG loop recorders", Europace, vol. 11 , no. $6, \quad 2009, \quad$ pp. $836-836$. https://doi.org/10.1093/europace/eup 142.

[8] Celbit, "Chaleco "inteligente" envía mensajes sobre ritmo cardíaco", 2018. [Online]. A v a i l a ble a t : https://www.celbit.net/2013/01/04/chalecointeligente-envia-mensajessobre-ritmocardiaco/.

[9] J. Bustamante, J. Sáenz, S. Marín and A. Amaya, "Desarrollo del componente de hardware de un dispositivo de telemonitoreo inalámbrico de eventos cardiacos", Scientia et Technica, vol. 14, no. 39, 2008, pp. 445-448.

[10] L. Gravitz, "Biosensors Comfortable Enough to Wear 24-7", 2010. [Online]. Available at: https://www.technologyreview.com/s/41968 3/biosensors-comfortable-enough-towear24-7/.

[11] Medset, "The long-term ECG recorder that really lives up to its name", 2018. [Online]. Available at: https://www.medset.com/en/products/holte r-ecg/telesmart/.

[12] P. Barrett, R. Komatireddy, S. Haaser, S. Topol, J. Sheard, J. Encinas, A. Fought and E. Topol, "Comparison of 24-hour Holter Monitoring with 14-day Novel Adhesive Patch Electrocardiographic Monitoring”, The American Journal of Medicine, vol. 127, no. 1, $2014, \quad$ p p . $11-17$. https://doi.org/10.1016/j.amjmed.2013.10.0 $\underline{03}$.

[13] iRhythm, "Uninterrumped comprehensive EKG interpretation”, 2018. [Online]. Available at .

http://irhythmtech.com/productsservices/zio-xt.

[14] B. Ouyang, "ZIO Wireless Patch May Be Better Option Than Holter Monitors for Cardiac Arrhythmia Diagnosis", $20001 \quad 4$. [Online]. Available at: https://www.medgadget.com/2014/01/ zio-wireless-patch-may-be-better-optionthanholter-monitors-for-cardiacarrhythmia-diagnosis.html.

[15] Chenai Medipoint, "ECG", 2014. [Online]. Available at: http://www.chennaimedipoint.com/vpatch(p).html.

[16] Medtronic, "SEEQ Mobile cardiac telemetry system", 2018. [Online]. Available at: https://www.medtronic.com/us-

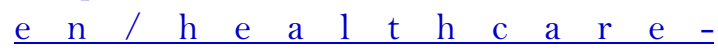
professionals/products/cardiacrhythm/cardiac-monitors/mct.html.

[17] Heartbook app, "Heartbook Technology Development H1 S-MCT User Manual”, 2018 . [Online]. Available at: https://usermanual.wiki/HeartbookTechnology-Development/H1.

[18] N. Selvaraj, "Performance of adhesive wireless patch sensor for screening of sleep architecture in normal and apnea", Sleep, vol. 40, no. 1, 2017 , p p. $16-17$. 
[19] VitalConnect, "A Breakthrough in Wearable Health Technology”, 2018. [Online]. Available a $t$ :

https://vitalconnect.com/solutions/vitalpatc $\underline{\mathrm{h} / \mathrm{s}}$

[20] Philips, "Philips wearable biosensor Keep watch, know more, respond quickly", 2014. [ O n l i n e ]. A v a i l a ble a t : https://www.usa.philips.com/healthcare/cli nical-solutions/earlywarningscoring/wireless-biosensor.

[21] LifeWatch, "Mobile Cardiac Telemetry", 2018. [Online]. Available at:

https://www.lifewatch.com/HealthcareProfessionals/Mobile-CardiacTelemetry.html.

[22] B. Yu, L. Xu and Y. Li, "Bluetooth Low Energy (BLE) based mobile electrocardiogram monitoring system”, IEEE International Conference on Information and Automation, Shenyang, 2012, pp. 763-767. https://doi.org/10.1109/ICInfA.2012.62469 21.

[23] N. Selvaraj, "Long-term remote monitoring of vital signs using a wireless patch sensor", IEEE Healthcare Innovation Conference (HIC), $\mathrm{S}$ e a t $\mathrm{t}$ e , 2014 , p p . $83-86$. https://doi.org/10.1109/HIC.2014.7038880.

[24] J. Steinberg, et al., "2017 ISHNE-HRS expert consensus statement on ambulatory ECG and external cardiac monitoring/telemetry", Heart Rhythm, vol. 14, no. 7, 2017, pp. 55-96, 2017. https://doi.org/10.1016/j.hr thm.2017.03.038

[25] VitalConnect, "Paving the way for healthcare innovations", 2018. [Online]. Available at: https://vitalconnect.com/markets/clinicaltrials/.

[26] J. Teo, "Early prolonged ambulatory heart monitoring in patients with stroke", United K in g d o m, 2016 . https://doi.org/10.1186/ISRCTN50253271.

[27] Bardy Diagnostics, "Comparison of Continuous Sternal ECG Patch Monitors

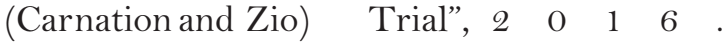
[Online], Available a t : https://clinicaltrials.gov/ct2/show/NCTo20 $\underline{31484 .}$.
[28] iRhythm, "Zio Is the Faster, More Reliable Way to Diagnose Your Irregular Heart Rhythm", 2018 . [Online]. Available at: http://irhythmtech.com/patients/how-itworks.

[29] Patch Cardio, "How t o s e t u p vpatch", 2018. [Online]. Available a t : .

https://www.vpatchmedical.net/how-to.

[30] Alibaba, "Bluetooth ECG H o l t e r ", 2018. [Online]. Available at:

https://spanish.alibaba.com/g/bluetoothholter.html.

[31] J. Pastor, "Cómo de exactos son los medidores de frecuencia cardiaca de los wearables", 2018. [Online]. Available at: https://www.xataka.com/wearables/comodeexactos-son-los-medidores-de-frecuenciacardiaca-de-los-wearables.

[32] M. Webb, "Apple Is Developing an EKG Heart Monitor for Its Smartwatch”, 2018. [Online ]. A vail a ble a t: https://www.bloomberg.com/news/articl es/2017-12-21/apple-issaid-to-developekg-heart-monitor-for-future-watch.

[34] J. Kim, D. Son, M. Lee, C. Song, J. Song, J. Koo, D. Lee, H. Shim, J. Kim, M. Lee, T. Hyeon and D. Kim, "A wearable multiplexed silicon nonvolatile memory array using nanocrystal charge confinement", Science Advances, vol. 2, no. 1, 2016 , 2016 .

https://doi.org/10.1126/sciadv.1501101.

[35] J. Pla, M. A. Bonet-Aracil and E. Bou, "Caracterización de sensores integrados en prendas textiles deportivas para la práctica del triatlón”, thesis MSc., Universidad Politécnica de Valencia, Spain, 2016.

[35] D. Evans, "Internet de las Cosas- Cómo la próxima evolución de Internet lo cambia todo", 2011. [Online]. Available at: https://www.cisco.com/c/dam/global/es_mx /solutions/executive/assets/pdf/internet-ofthings-iot-ibsg.pdf. 
[36] Cisco, "IPv6 Addressing and Basic Connectivity Configuration Guide, Cisco IOS XE Release 3S”, 2016. [Online]. A v a i l a b l e a t : https://www.cisco.com/c/en/us/td/docs /iosxml/ios/ipv6_basic/configuration/xe -3s/ip6b-xe-3s-book/ip6-add-basic-connxe.html.

[37] GSMA, "Understanding the Internet of Things (IoT)”, 2014. [Online]. Available at: https://www.gsma.com/iot/wpcontent/uploads/2014/08/cl iot wp 07 _14.pdf.

[38] D. Goldman, “QQué es la tecnología 5G? Todo lo que necesitas saber", 2018. [Online ]. Avail able a t: http://cnnespanol.cnn.com/2018/01/31 /5g-que-es-como-funciona-quecambia/. 